\title{
Development of an observatory for spatial planning in South Africa: a best practice review
}

\author{
Serena Coetzee ${ }^{1}$, Julian Smit $^{2}$ \\ ${ }^{1}$ Centre for Geoinformation Science, Department of Geography, Geoinformatics and Meteorology, University of \\ Pretoria, Pretoria, South Africa serena.coetzee@up.ac.za \\ ${ }^{2}$ Department of Architecture, Planning and Geomatics, University of Cape Town, Rondebosch, 7701 Cape Town, South \\ Africa
}

DOI: $\underline{\text { http://dx.doi.org/10.4314/sajg.v4i3.13 }}$

\begin{abstract}
The National Development Plan (NDP) of South Africa describes a 2030 vision for the country. The NDP proposes an observatory as one of the measures to develop capabilities for effective spatial decision-making and implementation. This article presents results of a review of observatories with the aim to unpack the details for setting up the proposed observatory. A review of mainly South African observatories was conducted in order to clarify the focus of the observatory (i.e. its purpose and main operations) and how it should be set up (i.e. stakeholders to be involved and hosting options). The review draws on interviews, questionnaires and a workshop with stakeholders, experts and key players. A review of relevant scientific literature and observatory websites was also done. Results underline the importance of drawing on existing data collection, integration and analysis initiatives, as well as the coordinating role such an observatory will have to play.
\end{abstract}

\section{Introduction}

Chapter 8 of the NDP (2012) deals with the transformation of human settlements and the national space economy. An observatory is proposed as one of the measures to develop capabilities for effective spatial decision-making and implementation. Urban and rural space would be observed with a focus on the development and management of the terrestrial (as opposed to extra-terrestrial) space. This article presents the results of background research to unpack the details of setting up of the observatory. A review of mainly South African observatories was conducted in order to clarify the focus of the observatory (i.e. its purpose and main operations) and how it should be set up (i.e. stakeholders to be involved and hosting options). The review draws on interviews, questionnaires and a workshop with stakeholders, experts and key players. A review of relevant scientific literature and observatory websites was also done.

The remainder of the paper is structured as follows: section 2 provides background on observatories, as well as more details about the objectives of the proposed observatory. Section 3 presents the results of the review of observatories, while in section 4 hosting options and organisational structure are analysed. Section 5 concludes with recommendations.

\section{Background}

\subsection{The 'observatory' concept, history and origins}

The history of using quantitative indicators for policy-making goes back to the 1940s when monthly economic indicators were published to measure the buoyancy of the US economy. The success of these indicators prompted social scientists in the 1960s and 1970s to develop indicators that measure social change. In the 1990s, community indicators for broad environmental concerns related to sustainability and quality of life emerged (Wong 2006).

Observatories were established in the 1990s to collect and disseminate community indicators related to spatial planning. Examples are the European Observation Network for Territorial Development and Cohesion (ESPON) and the UN-Habitat Global Urban Observatory. UN-Habitat defines an observatory as "a network of stakeholders responsible for producing, analysing and disseminating data in a meaningful set of indicators that reflect collectively in prioritizing issues on sustainable development. Data and information resources produced by the local networks are used to support decision-making and formulation of better-informed policies at various scales of governance" (UN-Habitat n.d., p 18).

UN-Habitat (n.d., p 15) advises that an urban observatory should not be "a policy think tank or an isolated academic research centre", rather it should coordinate knowledge- and decision-making to "generate high-quality data on specific indicators that inform urban planning, resource allocation and development". Governments, as urban managers and policymakers, must be fully engaged in data production and analysis in order to ensure that the information is put to work for the good of citizens". The very success of an observatory is dependent on its successful interactions with the users of the observatory outputs. The structural characteristics of the observatory and user organizations, and their interactions, will have an influence on the performance of both (Dessers et al. in Nedović-Budić et al. 2011).

In their review of 180 French data observatories, Feyt and Roux (2012) distinguish three "invariants in the expected functionalities of an observatory: 
- the capacity to collect and integrate quantitative or qualitative data and to check data reliability and coherence;

- $\quad$ the ability to aggregate, compare and analyse data that are frequently on different themes;

- the competence in presenting information in figures (graphic and cartographic) and comments, and in communicating the results of analyses using various formats and supporting materials (study reports, posters, web sites, etc.)".

Feyt and Roux (2012) acknowledge that observation is linked to the notion of obtaining knowledge with a view to taking subsequent action and is therefore a technical, scientific and political function. Georgiadou et al. in (NedovićBudić et al. 2011) report the emergence of bottom-up infrastructures based on volunteered geographic information (VGI), geo-browsers, and citizen-sensors, using mobile phone and occasional Internet access, in developing countries. Citizens are thus enabled to participate and influence local decisions and services, which is consistent with the aims of the NDP.

\subsection{Objectives of the proposed observatory}

Chapter 8 of the NDP (2012) proposes a strategy to deliver a South Africa by 2030 where one can observe meaningful and measurable progress in reviving rural areas and in creating more functionally integrated, balanced and vibrant urban settlements. For this to happen the country must, amongst others, build the required capabilities in the state and among citizens. An observatory is proposed as one of the measures to develop capabilities for effective spatial decision-making and implementation. Capabilities refer to the "institutional architecture, processes and resources needed for effective spatial governance, as well as the required knowledge sets, skills, learning networks, innovation capacity and leadership" (NPC 2012, p 289).

The package of proposals in Chapter 8 of the NDP includes a National Spatial Framework (NSF), supported by a National Spatial Fund, informed by an observatory for spatial data assembly and analysis. This implies that the observatory needs to provide evidence in support of national level spatial planning and evidence to support prioritisation of funding. Although access to local-level data for municipal spatial planning purposes is also currently a challenge, this gap will not be addressed directly by the observatory.

The focus of the proposed observatory should be on the form of future towns and cities, as well as the future development of rural land and settlements. Forces shaping global and local material conditions should be taken into account, as well as interdependencies with climate change, water resources, food security, sustainable energy supply, and economic and social infrastructures. Typical functions would be to analyze spatial planning policy implementation (note not monitor, as this is the responsibility of line departments) and to simulate and evaluate impacts of policies and decisions (a 'crystal ball gazing' sort of activity).

According to the objectives of the observatory described in the NDP, the focus of the proposed observatory should be on integration, analysis and interpretation of data. Collection of evidence (data) is required to achieve this. In South Africa, primary acquisition (collection) of data typically falls under the provenance of existing institutions and organisations. For example, spatial data falls within the ambit of the South African Spatial Data Infrastructure (SASDI) (Spatial Data Infrastructure Act No 53 of 2003) and custodians for spatial datasets have been identified. Similarly, Statistics South Africa (StatsSA) maintains economic, demographic, social and environmental data (Statistics Act 6 of 1999).

While South Africa has a fairly sophisticated system for collecting and disseminating data through StatsSA, certain challenges have been identified (Van Huyssteen et al. 2009, NPC 2011). For example, some forms of data are not available at adequate levels of disaggregation, updates are infrequent, and SASDI, which aims to support analysis and decision-making, is still in its infancy. The proposed observatory should not duplicate existing efforts, but rather find ways to cooperate and collaborate with these.

According to the NDP, "the observatory could be linked to a ministry or be located in one of the major research institutions in the country. Either way, it will have to be created via a legal framework that enables collecting, integrating and managing information from various sector departments and agencies." (NPC 2012, p 291).

\section{Review of observatories}

In this section a qualitative analysis of the review of ten observatories (eight from South Africa, one from Ireland and one from Europe) is presented; see Table 1. The list of observatories was compiled based on a review of literature and augmented by the authors' experience and suggestions from project participants. Feedback from experts and key players was gathered through:

a. Interviews with a number of stakeholders representing prominent national organisations dealing with spatial data infrastructures / observatories / spatial planning processes; in particular: 
- Department of Rural Development and Land Reform, Chief Directorate: Spatial Planning and Information (DRDLR-SPI)

- Department of Rural Development and Land Reform, Chief Directorate: National Geo-spatial Information (DRDLR-NGI)

- $\quad$ Department of Science and Technology (DST)

- $\quad$ Statistics South Africa (Stats SA)

- $\quad$ Spatial temporal evidence for planning (StepSA) project, Built Environment, CSIR

b. A workshop held on 4 February 2014 at the Union Buildings in Pretoria, attended by relevant stakeholders from various levels/departments of government and research organisations.

The analysis draws on questionnaires responses, interviews, the workshop and scientific literature. Full details of the questionnaires are available in NPC (2015).

Table 1. List or reviewed observatories

\begin{tabular}{|l|l|l|}
\hline AIRO & All-Island Research Observatory (Ireland) & $\underline{\text { www.airo.ie }}$ \\
\hline CCT-SDI & $\begin{array}{l}\text { City of Cape Town, Department: Strategic } \\
\text { Development Information and Geographic Information } \\
\text { System (GIS) }\end{array}$ & $\begin{array}{l}\text { www.capetown.gov.za/en/stats/Pag } \\
\text { es/default.aspx }\end{array}$ \\
\hline CUO & Cape Urban Observatory & $\underline{\text { http://cuo.geomatics.uct.ac.za/ }}$ \\
\hline ESPON & European Spatial Planning Observatory Network & $\underline{\text { www.espon.eu }}$ \\
\hline GCRO & Gauteng City and Regional Observatory & $\underline{\text { www.gcro.ac.za }}$ \\
\hline SAEON & South African Environmental Observation Network & $\underline{\text { www.saeon.ac.za }}$ \\
\hline SANBI & South African National Biodiversity Institute & $\underline{\text { www.sanbi.org }}$ \\
\hline SANSA & South African National Space Agency & $\underline{\text { www.sansa.org.za }}$ \\
\hline StepSA & Spatial temporal evidence for planning (StepSA) & $\underline{\text { http://stepsa.org }}$ \\
\hline WCPG-SI & $\begin{array}{l}\text { Western Cape Provincial Government, Office of the } \\
\text { Premier, Chief Directorate: Strategic Management } \\
\text { Information, Directorate: Spatial Information }\end{array}$ & $\begin{array}{l}\text { www.westerncape.gov.za/general- } \\
\text { publication/western-cape-spatial- }\end{array}$ \\
\hline
\end{tabular}

\subsection{Purpose of the observatory}

Regardless of the different domains of application, the purposes of reviewed observatories have in common that they aim to collect evidence (data or information) to inform policy development and decision-making. In other words, the observatories do not develop policies and they don't take decisions, but play a supporting or advisory role to these functions. Apart from primary evidence collection, many observatories also provide the coordinating framework for data integration from various sources.

Analysis of the collected evidence, as well as interpretation, modelling and scenarios, are further activities in support of policy development and decision-making mentioned in the observatory purposes. Dissemination and communication of observatory output (data, information, analysis results, etc.) and assistance with interpretation of the results are also mentioned in the purposes.

The purpose of many of the reviewed observatories includes fulfilment of a legal mandate associated with South African legislation, e.g. South African National Biodiversity Institute (SANBI), South African National Space Agency (SANSA), South African Earth Observation Network (SAEON) and the City of Cape Town, Department: Strategic Development Information (CCT-SDI).

Some observatories refer to a monitoring role in their purpose. For example, a governance and policy monitoring 'tool' to "measure the results of provincial strategic objectives and its outcomes spatially" is currently under development by the Western Cape Provincial Government, Office of the Premier, Chief Directorate: Strategic Management Information, Directorate: Spatial Information (Western Cape Provincial Government 2013). Another example is the proposed development of a land use monitoring tool, by the Chief Directorate, Spatial Planning Information, in the Department of Rural Development and Land Reform described as a "nationally coordinated land use 
monitoring tool (system) that can be used to assess, monitor, and model the development of urban and rural environments against the backdrop of spatial plans/spatial planning legislation" (CSIR 2013).

Based on discussions with key role players and feedback from the stakeholder workshop, getting side-tracked by operational and strategic line department functions, such as monitoring progress on implementation of individual policies, is a significant risk for an observatory and should be avoided. Hosting options to avoid this risk are further discussed in 4. Workshop participants also cautioned against an observatory purpose that is too narrow, because once the observatory starts producing output, it is likely that wider needs and applications will emerge. While the observatory should start small to ensure a successful setup phase, there should be room to grow and evolve its purpose.

Interviewees were of the opinion that a national observatory should include in its purpose functions that municipal or provincial observatories cannot and should not fulfil. As a first example, the national observatory could integrate regional data and indicators into national views and scenarios for the country. In Europe, for example, ESPON integrates data from national observatories and research institutes to provide information about European territorial dynamics (ESPON Management Authority 2006). However, a national observatory should not constrain itself by existing administrative boundaries because human settlement dynamics do not necessarily constrain themselves by these boundaries. As a second example, while local and regional observatories might be constrained to focus on short to medium term goals, a national observatory is in the ideal position to look beyond that at scenarios and long-term goals for the future.

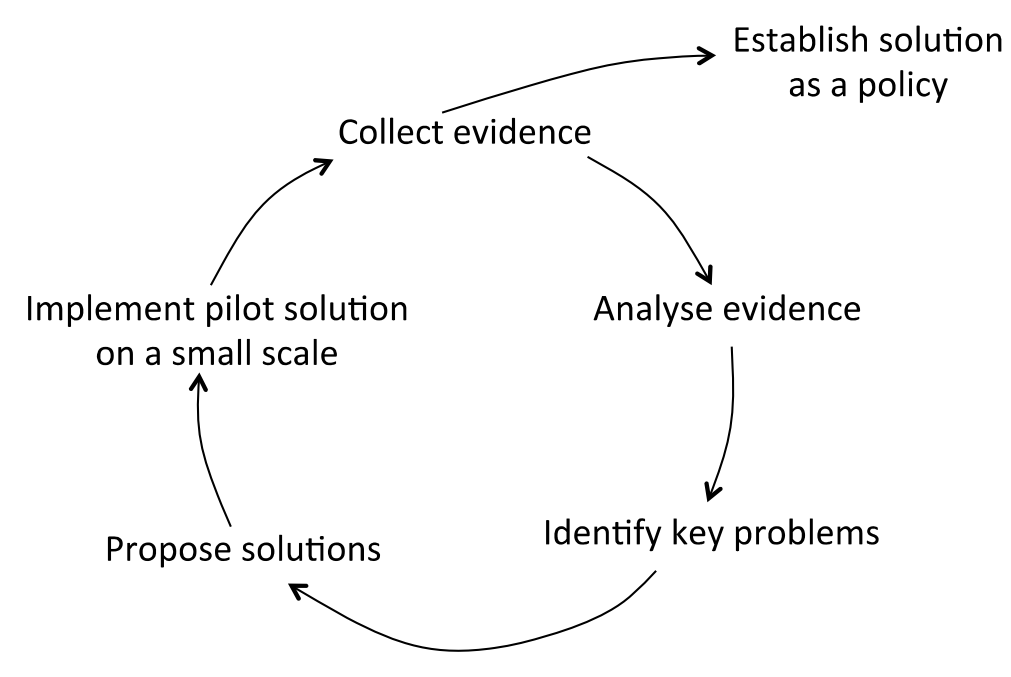

Figure 1. Policy development through learning-by-doing (NPC 2015)

Compared to the other reviewed observatories, SANBI's purpose is unique because it actually pilots best-practice management models in partnership with stakeholders. As an analogy, the proposed observatory could take its purpose one step further to inform policy development through learning-by-doing (see Figure 1). Extending the purpose to include learning-by-doing would lead to improved policy development and lower the risk of failed policies because they are tested on a small scale before widespread implementation. However, the implementation part of learning-by-doing requires the involvement of (implementer) stakeholders, which does not match the data collection-analysisdissemination role of the observatory described in the NDP.

Civil society engagement with government through participatory and voluntary e-Governance processes is another purpose for consideration for the proposed observatory, which is in line with the NDP's objective of 'citizen led ... planning processes'. Not only is the value of data or information enhanced through open access, but it also allows citizens to provide input to data structures used by the observatory (see Figure 2 in next section). Having participatory governance should be seen as desirable, but beyond that, ordinary citizens may act as data producers (the idea of voluntary geographic information or crowdsourcing) in addition to being potential users. Approaches, such as Participatory GIS (PGIS), volunteered geographic information (VGI) and crowdsourcing need to be considered as part of the data supply chain for a holistic, citizen-engaged observatory.

\subsection{Observatory stakeholders}

The questionnaire poses the question of who the stakeholders of the observatory are and why. Additional questions explored the interest of stakeholders and their roles in the observatory, including whether a legal obligation or mandate was fulfilled through the observatory. Observatories were asked how they engaged with the intellectual capital at universities, how they engaged with stakeholders and how topics or themes were prioritized. 
Responses to questionnaires indicate that observatory stakeholders are involved as funders, as collaborators on projects (e.g. participating in the analysis activity), as data providers or as users of observatory output. Funders could include the host institute, which sometimes indirectly funds the observatory by providing office space, administrative services, etc. Collaborators work on projects and are typically from universities or research institutes. Observatory stakeholders typically share a common thematic focus (e.g. environmental or spatial planning) and are brought together by challenges related to data and analysis or research requirements. They hope to gain value from symbiotic collaboration through an observatory.

Municipalities are at the 'coal face' where the impact of policies is directly tangible and visible. Most observatories have stakeholder representatives from municipalities, typically as data providers or as users of observatory output, but sometimes also as funders and collaborators.

All observatories have universities as stakeholders in various roles and emphasized the importance of academic involvement. Academics are involved as scientific project collaborators. They are valued for their contribution as scientists, as well as for their objectivity, achieved through peer-review and autonomy. Academics are involved in capacity building, e.g. by supervising postgraduate students on observatory related projects or by presenting courses on observatory-relevant topics. Universities are sometimes involved as partners. For example, some observatories are set up and funded as research projects at universities, e.g. the All-Island Research Observatory (AIRO) and the Cape Urban Observatory (CUO), others are hosted by universities, e.g. the Gauteng City Region Observatory (GCRO).

Some observatories have individual stakeholders with mostly an advisory role (e.g. CUO). In other observatories an Advisory Board or Committee (e.g. GCRO) provides the advisory function. In the latter example, Advisory Committee Members are asked to review observatory output before it is released for publication. However, the reviewed observatories were ambivalent about whether the potential value of their advisors was optimally exploited.

Prioritization of topics or themes is (naturally) heavily influenced by the stakeholders who fund the observatory. There are advantages and disadvantages to this. For example, the funder's influence ensures that money is spent on relevant and appropriate topics, but one should be wary of funders compromising the quality of observatory output. Many observatories report that partner stakeholders participate in deciding on the prioritization of topics and themes. Some observatories report that personal interests of scientists also play a role. Generally, user requirements are also considered when deciding on the topic and scope of projects.

Coordination among observatory stakeholders happens in various ways. From the questionnaire responses and from information gathered through interviews it is evident that stakeholder roles and coordination mechanisms should not rely on human memory and individual relationships, but need to be documented and agreed at organizational level. This ensures continuity, for example, when individuals leave the organization or when the organization is restructured; also, agreements in which roles and responsibilities are clearly outlined avoid conflict.

\subsection{Communication and dissemination of observatory output}

All observatories state that policy and decision makers are their primary target audience (see Figure 2); some (e.g. CUO and SAEON) mention academics specifically. These responses confirm that an observatory should ensure that its outputs are usable by policy makers. The first ESPON evaluation report noted that outcomes should not only be of academic value, but that it is essential for outcomes to be usable by policy makers (EC 2005). This sentiment was echoed in the interviews in this project and is confirmed in the UN-Habitat guide on setting up an observatory (n.d.), which regards policy makers as the beneficiaries of an urban observatory.

Interviewees regard output funded by the public sector as a public good that is freely available to the general public. In this way it is available to anyone for improving the lives of citizens, but also allows for 'peer review' by society. All observatories have at least a website where some of its outputs (e.g. presentations, reports and static maps) are accessible. Some observatories make their output available as online maps (e.g. GCRO); some also allow data downloads from the website. Many observatories communicate with users through email newsletters or vignettes. A 'map of the month' is a common feature, published either on the website or through email distribution. Observatory output is also published through peer-reviewed scientific journals. 


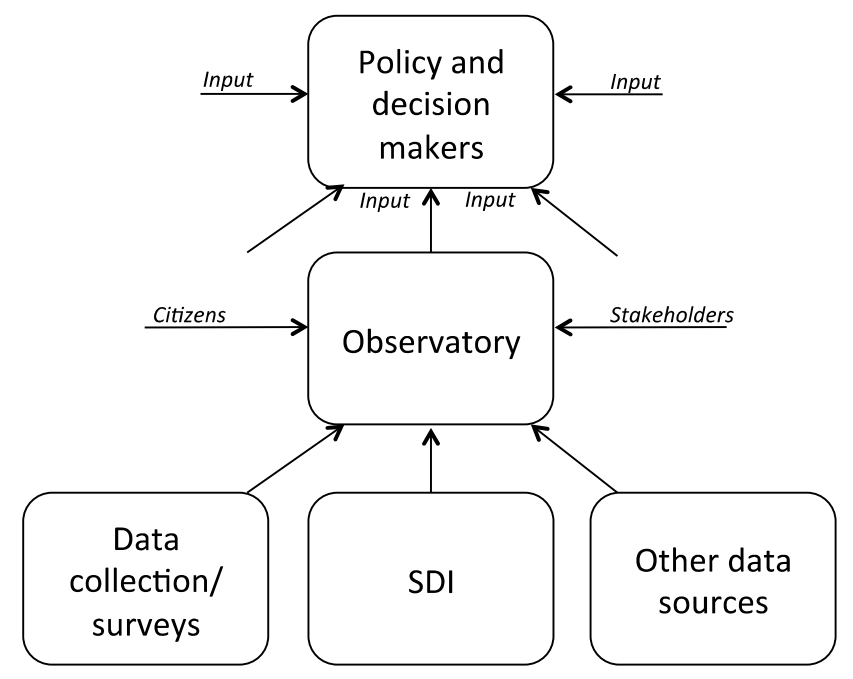

Figure 2. The observatory as one of many inputs to inform policy and decision makers (NPC 2015)

Observatories report that much time and effort is required in communicating observatory output. For example, AIRO spends considerable time training users on how to use their data; GCRO puts much effort into presenting the observatory output so that it is generally understandable not only by policy and decision makers, but also by the general public. Many observatories warn that one could easily get swamped in requests for data, which are not necessarily core to the observatory's function.

Training is not only required for the implementing institutions of the observatory, but equally important, it should include the users of the observatory outputs. According to UN-Habitat (n.d., p 29) "a major weak link in developing urban indicators systems and observatories is the difficulty that government employees and other stakeholders have in implementing and using the developed processes. Both high-level and mid-level managers, as well as technical staff, should receive training in what indicators and observatories are all about and how the tools can help them in their work". A key challenge is employee, and particularly senior management, turnover in many cities, which necessitates on-going training efforts. Because of this turnover, training is needed not only in the initial stages of implementation but also at later stages.

Feedback from the stakeholder workshop and interviews suggests that a culture of evidence-based planning is not common in South Africa. The proposed observatory will therefore have to promote and foster such a culture and build capacity in this regard, for example, through postgraduate research projects and/or professional training interventions.

However, the observatory should not focus on the dissemination of information and maps only. An observatory can stimulate discussion and serve to promote participatory governance through appropriate integration of socio-economic, spatial planning and political content. The example of the Observatorio Das Metropoles (in Brazil) comes to mind, where they put out an e-mail newsletter with content such as: articles on urban mobility, transport and urban economic development, the origin of chaos, sustainable urban mobility, etc. These articles serve to keep the citizens (and policy makers) informed of research developments affecting their lives.

\subsection{Staff and funding considerations}

Respondents agreed that a dedicated and full-time team of researchers is required to make an observatory work (i.e. researchers should be permanently employed). A multi-disciplinary team of researchers from the natural sciences, engineering and social sciences is needed for the futuristic analyses and modelling required in the proposed observatory.

Interviewees recommended that the core team initially draws on staff with relevant experience from existing observatories (e.g. CUO, GCRO, SANBI, SANSA, etc.) and related initiatives, such as Spatial temporal evidence for planning in South Africa (StepSA), South African Spatial Data Infrastructure (SASDI) and Stats SA. to ensure that lessons learnt are successfully transferred to the proposed observatory. Such involvement can be in the form of employment, contracting, consulting and/or secondment. An incubation process was proposed at the workshop; that is, starting the proposed observatory with a small core team on a limited number of key issues before expanding to a larger set of issues with a wider focus.

Interviews and literature confirm that a successful strategy is to start small with early quick wins before expanding. Interviewees suggested that it takes at least five years to set up and get an observatory 'up-and-running'. 
Further responses indicated that observatories typically outsource general-purpose work (e.g. IT support, website maintenance) and specific specialist expertise (if and when required). Observatory employees working in a single location facilitate communication and foster synergetic work among team members. Most observatories commented on the importance of observatory leadership understanding government processes and power structures and having the necessary people skills to understand the requirements of important stakeholders and to convey (possibly unpopular) results to them.

Regardless of the hosting option (see section 4), there was general agreement at the workshop that government should primarily fund the proposed observatory, for example, through a parliamentary grant and/or budget allocations from one or more national departments. Nevertheless, additional sources of funding, such as from the Development Bank of South Africa (DBSA) or international funding organizations, could be explored and utilized, if and when available. Measuring the monetary return on investment of an observatory however, is complex and difficult to achieve.

\section{Analysis of hosting options}

In this section hosting options for the proposed observatory are analysed based on a literature review and interviews with stakeholders and representatives of observatories. Requirements to be met by a hosting institution are described in 4.1.

Observatories can be hosted at a university, a national science council or research institute, a government department, a non-governmental organization (NGO) or in the private sector. In subsequent sub-sections 4.2 to 4.6 different types of hosting institutions are evaluated, keeping the South African landscape in mind. In practice, an observatory is typically jointly hosted by a collaborative agreement among different types of institutions (university, science council or research institute, government department, NGO and/or private sector company). Therefore this section does not aim to identify the optimal type of hosting institution, but rather describes the contributions and potential risks of different types of institutions to the above requirements. Considerations for the organizational structure of the proposed observatory are included in 4.7 .

\subsection{Hosting requirements}

Drawing on a review of scientific literature (ESPON 2005, Feyt and Roux 2012, Nebert 2009, UN_Habitat n.d.) and questionnaire responses, the following requirements were identified for the hosting of an observatory.

An observatory should

- be impartial;

- have credibility so that its outputs also have credibility;

- ensure that its work is objective and of high scientific quality;

- be able to attract an appropriate multi-disciplinary team of people;

- $\quad$ have the systems and administrative support required for its operations;

- have institutional or 'political' support from the leadership at the host institution(s);

- $\quad$ have the required authority to negotiate inter-organisational relationships; and

- $\quad$ provide outputs as a public good with open access.

A key tension in an observatory is the need to be impartial and objective, while at the same time providing sustained support to policy makers. The observatory leadership often has the difficult task of conveying an unpopular message (based on scientific evidence) to policy and decision makers who typically are the funders of the observatory.

\subsection{Hosting at a South African university}

Academics from a university promoting academic freedom are (supposed to be) impartial to the results of observatory output. Hosting an observatory at a university promotes objectivity and scientific quality because scientific peer-review is part of the academic system. The scientific method and peer-review also give credibility to evidence collection and analysis results.

Hosting at an academic institution facilitates access to experts at the forefront of their fields, contributing to the scientific quality of the observatory's work. The larger universities South Africa can draw on experts from the disciplines required in an observatory (see also 3.4 Staffing). However, remuneration at universities cannot compete with industry, which is a challenge for attracting (suitably qualified) people. For example, the GCRO indicated that they had to initially inflate salaries in order to attract qualified staff from industry. 
Larger universities in South Africa have the capacity to provide the required systems and administrative support to an observatory. Universities, in South Africa also, increasingly have to depend on external funds. Therefore, political support from university leadership for an observatory is more likely if it is associated with funding.

Because there are distinct organizational boundaries between a university and government departments, universities have to establish institutional relationships with government departments in order to establish stakeholder co-operation agreements. Also, there are typically more barriers to inter-organizational communication and coordination compared to coordination and communication within a single organization.

On the other hand, clear organizational distinction between an academic host institution and the target audience of observatory outputs (politicians, government officials, etc.) runs less risk of being distracted by operational matters and objectives. This helps to keep a clear focus on foresight. It is also advantageous if one has to be the bearer of bad news (e.g. if evidence suggests a failed policy).

Agreements about the intellectual property rights of research funded by the observatory would have to be negotiated with universities. By default, universities claim the intellectual property rights to research and copyright to research output done by their employers. However, it is common to negotiate special agreements for funded research, which makes publication of observatory output as a public good possible.

\subsection{Hosting at a South African national science council or research institute}

Scientific research is the core business of science councils, such as the Council for Scientific and Industrial Research (CSIR) and the Human Sciences Research Council (HSRC). Theoretically, employees of science councils should have academic freedom and therefore be impartial to observatory output, but there have been incidents in the past where this has been questioned (Nature 2008). Many of their employees publish in peer-reviewed journals (publication productivity is included in performance appraisals), which promotes objectivity and scientific quality and promotes credibility.

The science councils of South Africa employ scientists from many different disciplines who have experience in working on multi-disciplinary teams. These scientists have the appropriate expertise for the applied research required in an observatory. The councils also have a track record in conducting large-scale research projects and should therefore have the capacity to provide systems and administrative support to an observatory.

Science councils too have to increasingly rely on external funding, therefore political support from science council leadership is more likely if it is accompanied by additional funding. Similar to universities, there is an organizational distinction between the councils and an observatory's main target audience, with the same advantages and disadvantages. However the 2008 incident reported in Nature (2008) suggests potential challenges to conveying bad news.

Even though science councils are 'closer' to government than universities, they too need to establish institutional relationships with government departments in order to establish stakeholder co-operation agreements. Similar to universities, barriers to inter-organizational communication and coordination exist and agreements about the intellectual property rights of research funded by the observatory would have to be negotiated with science councils to ensure that observatory output is published as a public good with open access.

\subsection{Hosting by South African government}

An observatory hosted solely by a government department cannot be impartial to policy makers. It may be compromised in truthfully conveying results, for example, if results could influence or impact the observatory budget and future promotions of employees. It is perhaps only when funding comes from a government department, which does not have a vested operational interest in the observatory, that objectivity can be maintained. The influence of funders on the observatory is a potential concern no matter who the host institution is, and independence in the analysis and presentation of results needs to be carefully guarded to foster objectivity.

A government department should be able to attract a team of multi-disciplinary scientists for an observatory, either as permanent employees or as consultants (although in the latter case continuity might be at risk). Since government departments are not usually subjected to scientific peer review, alternative approaches have to be followed to ensure objectivity and scientific quality of work and to give credibility to outputs. For example, standards, reference groups, and/or independent reviews or audits could be used to ensure scientific quality and to give credibility to results. This could add to the cost of running the observatory.

Provided budget has been made available, a government department should have the capacity to provide the required systems and administrative support to an observatory. 
Similar to the impartiality, political support from leadership for an observatory might be compromised by line department objectives. Hosting an observatory within a department will always run the risk of being distracted by operational matters and therefore loosing focus on foresight, the actual purpose of an observatory.

There are three options for hosting an observatory by government in South Africa:

1. The first option is to establish the observatory as a branch of a national department. Such an option would allow the department to budget for the programme within its current budget and may not require special legislation for the incurrence of expenditure. As such, placing the observatory within the government would have the advantage of easy access to government resources. Nonetheless, the lengthy processes, channels, regulations and rules associated with government branches would inevitably frustrate programme implementation. Furthermore, as a branch the observatory would lose the fundamental flexibility that is required to mobilize resources externally. There is also the risk of getting distracted by the department's line objectives.

2. Establishing the observatory as a government component would provide a flexible model that responds to government's agenda while also supporting commercial activities. The observatory would thus be able to receive a mix of operating revenue sources comprising earned income, public funding and private donations. As a government component, supplementary details of the relevant governance arrangements would be required to guide the nature of the relationship between the relevant government department and the observatory. The national department and the observatory would annually agree on a set of specific projects, programmes and events to be delivered, approved in writing by the parties. The observatory would then implement and manage all day-to-day operations and functions in accordance with the conditions agreed between the parties.

3. The third option is to establish the observatory as a public entity intended to generate profits and declare dividends. This option has the most autonomy of the three options, as it operates in a competitive marketplace and is run in accordance with general business principles. However, this option is not favorable for the observatory for reasons that are described in the private sector hosting option in 4.6.

Stakeholder workshop participants on this project pointed out that while an observatory is for government, it does not have to be hosted by government. Instead of hosting the observatory within a government department, it could be a separate entity or government component attached to the government department in order to avoid operational distraction. Examples of observatories that are set up in this way are SANBI, SAEON and SANSA. Compared to hosting by a university or science council, inter-organizational barriers are lower if government hosts the observatory.

Generally, the South African government promotes access to information and open data. For example, current government funded observatories, such as the GCRO, provide observatory output as a public good with open access and the policy on spatial data access proposed by South African's Committee for Spatial Information supports free access to data. However, the proposed Protection of State Information Bill raises some concerns as it could be seen to provide a means of prohibiting this.

\subsection{Hosting at an NGO}

Hosting at an NGO has the advantage of independence from policy makers and is therefore likely to be impartial. However, similar to a government department, an NGO does not necessarily rely on scientific peer-review and has to find alternative ways to establish credibility and to ensure objectivity and scientific quality. However, NGOs are well positioned to facilitate citizen engagement with an observatory.

Provided the NGO can raise the required funds, it should be able to employ a team of multi-disciplinary scientists required for an observatory. Insufficient funding is likely to compromise the quality of outputs and, in the long run, the sustainability of the observatory.

According to UN-Habitat (n.d., p 28), "initiatives driven by NGOs and academic institutions appear to have less support from their governments". In order to engender political support, such initiatives have to "link indicators with action agendas that bridge issues and provide positive steps toward community improvement".

A small NGO with limited funding might struggle to provide the required systems and administrative support to run an observatory. There are many large international NGOs that would certainly have the capacity to provide administrative support, but they tend to have very specific thematic objectives and none operate in the space of the proposed observatory.

Because NGOs are distinct from government, they have the same challenges to inter-organisational relationships than universities and science councils. Their challenges might be even bigger, because they are 'further away' from 
government. Generally, NGOs are likely to support open access to observatory output, however, effective access to observatory output (e.g. online maps) could be compromised by a small NGO with insufficient funding.

\subsection{Hosting in the private sector}

Similar to an NGO, an observatory hosted in the private sector would be independent and is likely to be impartial. An observatory hosted in the private sector would have to raise its own funds and show a profit. It therefore runs the risk of prioritizing profit over objectivity and quality of the data. Such profit motives might also be regarded as a risk to the credibility of observatory outputs and measures will have to be put in place to ensure these - sometimes the free market sorts itself out ('if it's not good, nobody will pay for it'), alternatively, one has to make use of scientific peer review, reference groups or audits.

While the first four types of institutions might have a larger interest in providing observatory output as a public good to society, the private sector has to protect its business interests and the intellectual property of its goods and services. This could result in an undesirable situation where observatory outputs are too expensive and therefore not available to policy makers and government officials who need them.

Political support in a private sector company is likely to correspond directly to alignment with business objectives and profits associated with the observatory activities. The challenges regarding a NGOs inter-organizational relationships with government, are equally relevant for a private sector company.

Provided an observatory in the private sector shows the necessary profit, it should be able to employ a team of multi-disciplinary scientists required for an observatory, but if profit targets are not met, the quality of outputs and, in the long run, the sustainability of the observatory will be compromised. Similarly, sufficient income is necessary to provide the required systems and administrative support to run an observatory.

\subsection{Organizational structure}

Results from the literature review and from interviews with observatories suggest that it is not desirable to have a single centralised observatory, both geographically and from an organizational point of view. One weak point of a centralised observatory is that it has a single point of failure. Geographical centralization of an observatory is not ideal because experts in different regions (e.g. municipalities or provinces) are more likely to know their region, its challenges and the region's target audience and stakeholders.

A decentralised multi-level observatory could be set up with observatories in different regions feeding data to a central national observatory (see Figure 3). For example, an observatory could be structured to include multiple geographical levels:

- At the local level, observatories in metropolitan regions gather data about their regions. Due to insufficient capacity at South African municipalities, observatories for other municipalities are not recommended. Metropolitan observatories could be hosted at universities, or even by NGOs.

- Provincial (spatial) observatories are hosted in each province, possibly at universities. They gather data from local observatories and collect data in areas not covered by metropolitan observatories. It is probably best not to be too prescriptive about the type of hosting institution, but rather let each province find a solution that suits its circumstances (available expertise, resources, etc.), provided it meets the hosting requirements.

- A single national (spatial) observatory gathers inputs from provincial observatories and national data custodians to provide foresight for the whole country. It should add value with national interests in mind, considering the country as a whole (as opposed to smaller regions at the other levels) and could be hosted by a national science council or by government.

A multi-level structure allows the observatory to tap into existing resources and capabilities in the country. It also provides the flexibility to adjust the focus at different regional levels because requirements might differ in different regions. The multi-tier structure could be further 'broken down' by analytical theme (see Figure 3), allowing for domain specialists to make best use of the observatory (Clarke, 2014). In fact, observatories for some themes already exist in South Africa, such as SAEON and SANBI. 


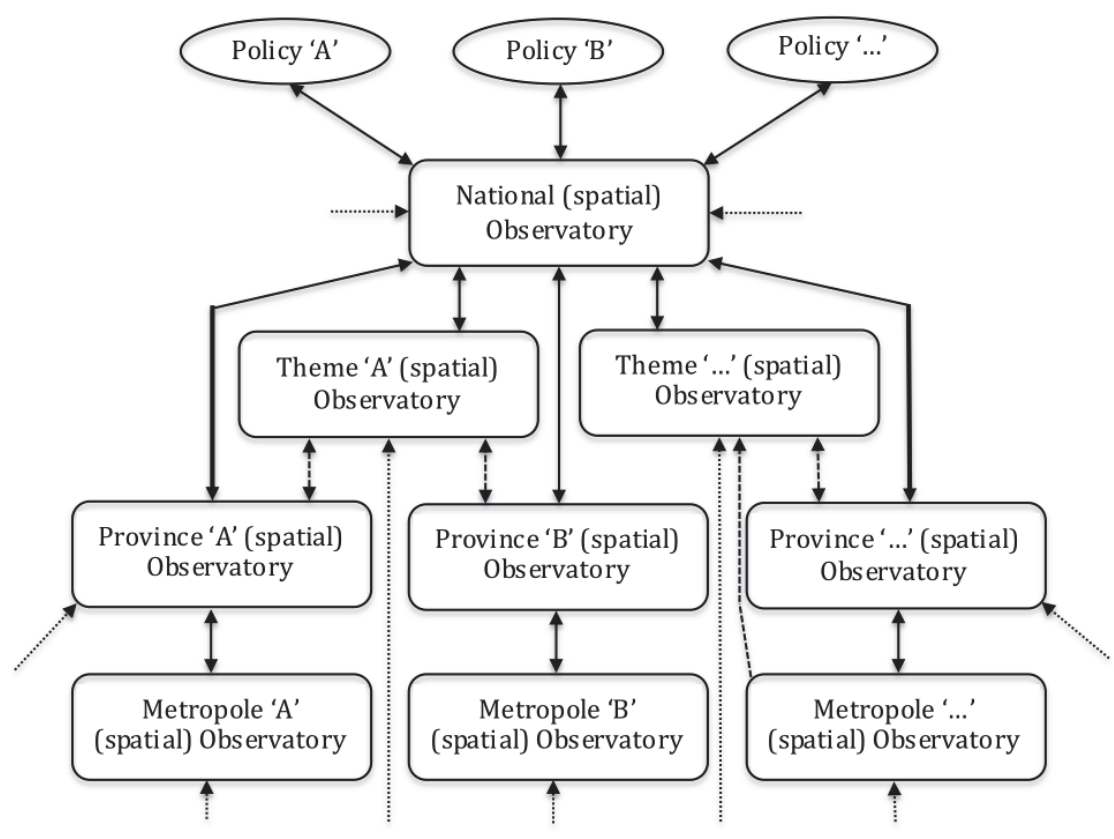

Figure 3. An example of a multi-tier and multi-theme observatory

According to the UN-Habitat guide on setting up an urban observatory (n.d., p 17), the multi-level observatories in countries, such as Mexico and Egypt, are "networks of local urban observatories facilitated by a national level partner who coordinates capacity-building assistance and compiles and analyses urban indicator data to assess national trends and needs".

\section{Recommendations and conclusion}

Based on review results and analysis of hosting options, this section discusses requirements for a national observatory in support of evidence-based planning in South Africa.

The primary thematic focus of the proposed observatory should be the transformation of human settlements and the national space economy. It should have a futuristic outlook, beyond the five-year election cycle. The focus should be on evidence to inform policies suitable for a changing future and on vision-building through a national spatial framework. It should not monitor policy implementation and should not be side tracked by operational and line department priorities.

The 'spatial data' to be analysed by the observatory should be understood widely, i.e. relevant data that is not necessarily geo-referenced, such as economic indicators by name of a geographic area, should also be included. Observatory output should be at the high end of the information value chain, i.e. the focus should be on knowledge produced from information and data. While the proposed observatory will have to integrate data from various sources, it should not constrain itself by existing administrative boundaries because human settlement dynamics do not necessarily follow these boundaries. Citizen engagement approaches, such as participatory GIS (PGIS), volunteered geographic information (VGI) and crowdsourcing should be considered as part of the data supply chain for a holistic, citizenengaged observatory.

Observatory stakeholders should have a common thematic focus. Universities should be involved in the proposed observatory, mainly to ensure scientific quality and objectivity, but also for capacity building purposes. Representation from local authorities in the proposed observatory is essential for effectively informing policies in support of human settlement transformation. Regular communication and engagement with stakeholders is important through direct communication and/or meetings, workshops and seminars. Stakeholder roles and coordination mechanisms should be formalised through documented agreements to ensure continuity and to avoid conflict.

Observatory output should be disseminated in a way that is understandable by policy and decision makers, the primary target audience. Observatory output should be considered as a public good that is freely available - so that outputs can be widely used to the benefit of citizens. The proposed observatory should communicate its output through a variety of media. Training and other mechanisms to empower users of observatory output should be considered to facilitate optimal use of the output. The proposed observatory will inevitably have to get involved in building capacity 
in and promoting and fostering a culture of evidence-based decision-making, for example, through training users in the use and application of observatory output and by supervision of postgraduate students.

The proposed observatory should start with a small set of indicators, which can grow and evolve. A systematic approach that allows efficient and effective spatial analysis over time should be pursued. The proposed observatory should draw on data from SASDI and other existing data providers, which can be augmented by observatory-specific surveys from time to time. Data sharing relationships and policies between the observatory and its data providers need to be formalised through documentation to ensure continuity and to avoid conflict.

Review results led to two possible hosting options, which are combinations of hosting institutions, and meet the identified hosting requirements:

1. Universities and/or one or more science council are the primary host of the proposed observatory to ensure impartiality, objectivity, scientific quality and thus credibility of freely accessible output. They provide a multidisciplinary team of experts and systems and administrative support. Government is involved in the hosting to provide strategic guidance and to facilitate inter-organizational relationships with government departments; for example, through representation on an Advisory Board.

2. The observatory is established as a government component in a national (mother) department in collaboration with universities and/or one or more science council. Annual agreement on specific projects, programmes and events to be delivered, is done in writing between the parties. All day-to-day operations and functions of the observatory are implemented indepdently in accordance with the conditions agreed between parties. The multi-disciplinary team of experts are employees of the government component, which also provides systems and administrative support. The involvement of universities and/or science councils ensures impartiality, objectivity, scientific quality and thus credibility of observatory output.

Regardless of the hosting option, it is recommended that political support from the primary host be negotiated and confirmed upfront through a documented agreement; that the organizational structure of the observatory should make it possible to draw on regional expertise, as well as similar initiatives in different but related themes; that the funding should primarily come from government; and that the observatory should initially be staffed with a small team of people who have gained relevant experience in existing observatories.

\section{Acknowledgements}

We would like to thank the interviewees, questionnaire respondents and workshop participants for their insightful contributions. We would like to thank Bea Drost and Phil Harrison for their comments on the report on which this article is based.

The research reported in this article was partially funded by the Secretariat of the National Planning Commission of South Africa.

\section{References}

Clarke D (2014). Interview with Dr. Derek Clarke, Chief Director, Department of Rural Development and Land reform, Chief Directorate: National Geospatial Information (DRDLR-NGI) and Chair of the South African National Committee for Spatial Information (CSI), January 2014.

CSIR (2013). Viability study: Development and implementation of a national land use change monitoring tool. Presentation to Department of Rural Developmen and Land Reform, Chief Directorate: Spatial Planning and Information, November 2013.

Dessers E, Van Hootegem G, Crompvoets J, Hendiks PHJ (2011). Integrating spatial information and business processes: The role of organizational structures. In: Nedović-Budić Z, Croempvoets J and Georgiadou Y (Eds), Spatial Data Infrastructures in Context: North and South. CRC Press: Boca Raton USA.

ESPON (2005). ESPON Mid-Term Evaluation Update. Final Report. Prepared by MVA for the ESPON Programme. September 2005.

ESPON 2013 Programme (2010). First ESPON Scientific Report: Scientific Dialogue on Cities, Rural Areas and Rising Energy Prices.

ESPON Managing Authority (2006). Annual report 2005. ESPON 2006 INTERREG III Programme. www.espon.eu/main/Menu_Programme/Menu_ESPON2006Programme/annualreports.html [accessed 27 November $2013]$.

European Commission (2005). Study on "territorial cohesion, lessons learned from the ESPON programme projects and strategy for the future”. Final report by Rambøll Management Brussels on behalf of the European Commission, 
South African Journal of Geomatics, Vol. 4, No. 3, August 2015

DG Regional Policy (2005 CE 160 AT 017). June 2006.

Feyt G and Roux E (2012). Functions and virtues of spatial data observatories: the French case. Proceedings of the Global Geospatial Conference 2012, Quebec, Canada.

Georgiadou Y, Budhathoki NR and Nedović-Budić Z (2011). An exploration of SDI and volunteered geographic information in Africa. In: Nedović-Budić Z, Croempvoets J and Georgiadou Y (Eds), Spatial Data Infrastructures in Context: North and South. CRC Press: Boca Raton USA.

National Planning Commission (NPC) (2011). Material conditions diagnostic. Available online at www.npconline.co.za/ [accessed 5 March 2014].

National Planning Commission (NPC) (2012). National Development Plan 2030. Our future - make it work. Pretoria: August 2012.

National Planning Commission (NPC) (2015). Background research to inform the setting up of the observatory proposed in Chapter 8 of the National Development Plan. Pretoria: March 2015.

Nature 2008, A South African water expert faced potential dismissal after criticizing his employer for failing to address a looming water crisis in the country, viewed 9 July 2015, www.nature.com/news/2008/081125/full/news.2008.1255.html.

Nebert, D. (Ed). (2009). The SDI Cookbook. Global Spatial Data Infrastructure (GSDI) Association.

South Africa (Republic of). (2003). Spatial Data Infrastructure Act No.54 of 2003. Cape Town: Government Printers.

South Africa (Republic of). (1999). Statistics Act 6 of 1999. Cape Town: Government Printers.

UN-Habitat (2010). State of the World's Cities 2010/2011 - Cities for All Bridging the Urban Divide. UN-Habitat, 2010, ISBN: 9781849711753. Available online at www.unhabitat.org/list.asp?typeid=15\&catid=646 [accessed on 27 January 2014].

UN-Habitat website (2014). www.unhabitat.org/ [accessed 24 January 2014].

UN-Habitat (n.d.). A guide to setting up an urban observatory. Available online at www.unhabitat.org/downloads/docs/LUO_guideline.pdf [accessed 27 November 2013]

Van Huyssteen E, Biermann S, Naudé A and Le Roux A (2009). Advances in Spatial Analysis to Support a more Nuanced Reading of the South African Space Economy. Urban Forum, 20:195-214.

Western Cape Provincial Government (2013). Department of the Premier, Business Plan 2013/2014. Internal report. Cape Town: March 2013.

Wong C (2006). Indicators for urban and regional planning. The interplay of policy and methods. Routledge: Oxon UK. 